\title{
A cytofluorimetric analysis of a Saccharomyces cerevisiae population cultured in a fed-batch bioreactor
}

\author{
Emanuela Palomba ${ }^{1 \oplus}$, Valentina Tirelli ${ }^{2 \odot}$, Elisabetta de Alteriis ${ }^{3}$, Palma Parascandola ${ }^{4}$, \\ Carmine Landi ${ }^{4}$, Stefano Mazzoleni ${ }^{5}$, Massimo Sanchez $\mathbb{1}^{2 *}$
}

1 Department of Research Infrastructures for marine biological resources (RIMAR), Stazione Zoologica "Anton Dohrn", Villa Comunale, Napoli, Italy, 2 Istituto Superiore di Sanità (ISS) Core Facilities, Rome, Italy, 3 Department of Biology, University of Naples "Federico II", Naples, Italy, 4 Department of Industrial Engineering, University of Salerno, Salerno, Italy, 5 Department of Agricultural Sciences, University of Naples "Federico II", Naples, Italy

๑ These authors contributed equally to this work.

* massimo.sanchez@iss.it

\section{OPEN ACCESS}

Citation: Palomba E, Tirelli V, de Alteriis E, Parascandola P, Landi C, Mazzoleni S, et al. (2021) A cytofluorimetric analysis of a Saccharomyces cerevisiae population cultured in a fed-batch bioreactor. PLoS ONE 16(6): e0248382. https://doi. org/10.1371/journal.pone.0248382

Editor: Alvaro Galli, CNR, ITALY

Received: February 24, 2021

Accepted: May 27, 2021

Published: June 10, 2021

Peer Review History: PLOS recognizes the benefits of transparency in the peer review process; therefore, we enable the publication of all of the content of peer review and author responses alongside final, published articles. The editorial history of this article is available here: https://doi.org/10.1371/journal.pone.0248382

Copyright: @ 2021 Palomba et al. This is an open access article distributed under the terms of the Creative Commons Attribution License, which permits unrestricted use, distribution, and reproduction in any medium, provided the original author and source are credited.

Data Availability Statement: The data are available on the public repository Flow Repository, the URL is: https://flowrepository.org/id/RvFrh23lz1PIoA8c b0yfMOqshSYSsKaoQnAwXegVm0jxo9rP7W6U zfchDWZglOfl.

\section{Abstract}

The yeast Saccharomyces cerevisiae is a reference model system and one of the widely used microorganisms in many biotechnological processes. In industrial yeast applications, combined strategies aim to maximize biomass/product yield, with the fed-batch culture being one of the most frequently used. Flow cytometry (FCM) is widely applied in biotechnological processes and represents a key methodology to monitor cell population dynamics. We propose here an application of FCM in the analysis of yeast cell cycle along the time course of a typical S. cerevisiae fed-batch culture. We used two different dyes, SYTOX Green and SYBR Green, with the aim to better define each stage of cell cycle during S. cerevisiae fed-batch culture. The results provide novel insights in the use of FCM cell cycle analysis for the real-time monitoring of $S$. cerevisiae bioprocesses.

\section{Introduction}

The yeast Saccharomyces cerevisiae is widely used in many industrial processes, including those related to its fermentation capacity. It is used in the food industry (brewing, winemaking, baking and food additives), in the production of biofuel and medically relevant biomolecules for therapeutic applications [1,2].

Due to the biotechnological importance of S. cerevisiae, yeast cultivation strategies have been improved to optimize the maximum achievable cell density in bioreactors. In particular, to increase the biomass yield, the cultural strategy of the "extended batch" or "fed-batch" culture $[3,4]$ has been developed to prolong the classic batch culture by a continuous or intermittent supply of fresh medium to the vessel so to achieve a high cell density [5]. This process has been traditionally used to produce baker's yeast [6]. 
Funding: Emanuela Palomba is supported by a $\mathrm{PhD}$ fellowship founded by Stazione Zoologica Anton Dohrn and by the NOSELF s.r.l (https://www. noself.it/) The funders had no role in study design, data collection and analysis, decision to publish, or preparation of the manuscript.

Competing interests: The author Emanuela Palomba is supported by a PhD fellowship founded by Stazione Zoologica Anton Dohrn and by the NOSELF s.r.I (https://www.noself.it). The funders had no role in study design, data collection and analysis, decision to publish, or preparation of the manuscript. This does not alter our adherence to PLOS ONE policies on sharing data and materials.
Further, different mathematical models have been developed and implemented to describe $S$. cerevisiae growth in different cultural conditions, to infer on and to predict yeast performance [7-10].

Developed mainly for medical and clinical purposes, flow cytometry (FCM) is a powerful technology that is finding application in agriculture and food science, including pro-biotic research and genetically modified organism development [11].

Moreover, it has been outlined how FCM technology can support other fields such as cytogenomics [12], proteomics [13], and marine cell biology [14,15].

FCM has been successfully applied in food microbiology for the assessment of safety during all steps of the food production chain, and widely used for the analysis of alcoholic beverages and dairy products [11,16-18]. Indeed, FCM analytical approaches allow high throughput detection, quantification, monitoring and, where necessary, the separation (i.e. cell sorting) of physiologically diverse microbial subpopulations in liquid food samples [19].

Given the positive outcome of these applications, different analysis systems have recently become available on the market to control the entire productive process or directly the final product [18].

S. cerevisiae growth can be efficiently monitored by FCM through the analysis of both the cell size and different cell properties (e.g: viability, vitality, apoptotic index, free radicals production, protein and nucleic acids content). This gives the possibility to correlate cellular attributes to yeast growth performance and predict the overall outcome of the bioprocess of interest [20-22].

In particular, protein and nucleic acids content showed a correlation with the growth phase and growth rate $[23,24]$, and with the amount of recombinant proteins produced by a yeast population growing in both continuous and fed-batch cultures [19].

It is well known that in yeast the differences in DNA content are correlated within the major phases of the cell cycle [25], so the progression of a proliferating population of yeast through the cell cycle can be monitored on the basis of the differences in DNA content and cellular size (Fig 1). In particular, FCM allows the identification of the pre-replicative phases (G0 and G1), DNA synthesis stage (S), post-replicative and mitotic (G2+M) phases. Moreover, cells with fractional DNA content typical of apoptosis can be further identified as a "sub-G1" population $[25,26]$. For example, the analysis of cells blocked in G0/G1 phase by using SYBR Green dye, gives information on nitrogen influence during alcoholic fermentation in S. cerevisiae [27]. By using the propidium iodide (PI), Jayakody and co-authors revealed that fermentation inhibitors impact S. cerevisiae population by blocking cells in G2/M phase [28]. Salma et al. [29] studied the cell cycle of S. cerevisiae in synthetic wine during viable but non-culturable state, so allowing the detection of cells which are not identified with routine laboratory methods.

Interestingly, Delobel et al., [32] used FCM to quantify the relative proportions of yeast cells in each cell cycle stage at different points of the growth curve of a population in batch culture by combining the data on cell size with the outputs obtained with different DNA binding dyes: SYTOX Green, PI, TO-PRO-3, 7- aminoactinomycin D and SYBR Green I. The authors concluded that SYTOX Green performs better than the other dyes in the identification of all the different cell cycle stages, also giving information on the percentage of cells in G0 phase, and allowing a clear discrimination between G0 and G1. Indeed, they stated that the peak commonly called "sub-G1" would not be representative of apoptotic cells but of the population fraction in G0 phase. Nevertheless, they concluded by recommending to use for yeast cell cycle analysis both SYTOX Green and SYBR Green I, under defined conditions and with appropriate reference samples [32]. 
a

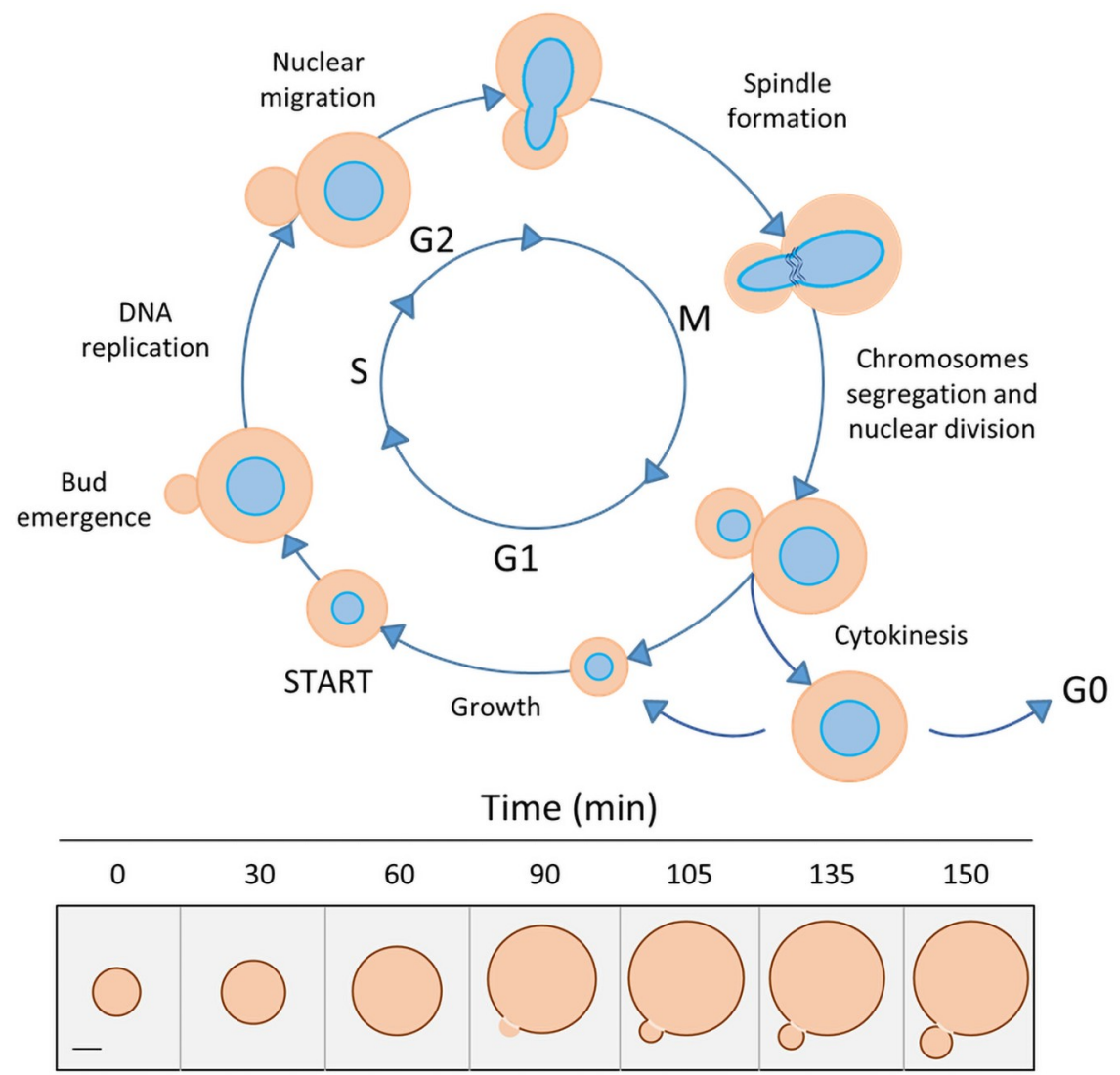

Fig 1. Schematic view of budding yeast cell cycles: Stages (a) and size (b). Scale bar on the left of panel B represents $2 \mu \mathrm{m}$. Images adapted from [30] (a) and [31] (b).

https://doi.org/10.1371/journal.pone.0248382.g001

In this work, we propose a FCM analysis of yeast cell cycle along the time course of a different type of S. cerevisiae cultivation, the fed-batch culture, based on the use of the two recommended DNA binding dyes (SYTOX Green and SYBR Green) and cell size. By comparing the results obtained with the two dyes, we define a suitable strategy of analysis for real-time monitoring of a yeast fed-batch bioprocess.

\section{Materials and methods}

The strain used for the experimental work was Saccharomyces cerevisiae CEN.PK2-1C (MATa ura3-52 his3-D1 leu2-3, 112 trp1-289 MAL2-8c SUC2) purchased at EUROSCARF collection (www.uni-frankfurt.de/fb15/mikro/euroscarf).

The experimental workflow is represented in Fig 2. The fed-batch culture was performed in a stirred $2 \mathrm{~L}$ working volume bioreactor (Bioflo 110, New Brunswick Scientific), as already described [7]. Briefly, the bioreactor filled with the medium was inoculated with an adequate aliquot of yeast pre-culture and growth was allowed to occur in batch mode. After $15 \mathrm{~h}$ (corresponding to time 0 of feeding phase), the feeding was started with a solution of $50 \% \mathrm{w} / \mathrm{v}$ glucose and salts, trace elements, glutamic acid and vitamins. The initial specific feeding rate was $0,16 \mathrm{~h}^{-1}$, which was progressively decreased along the time course of the experiment, according to a logistically decreasing specific growth rate, as predicted by the model by Mazzoleni et al. [7]. 

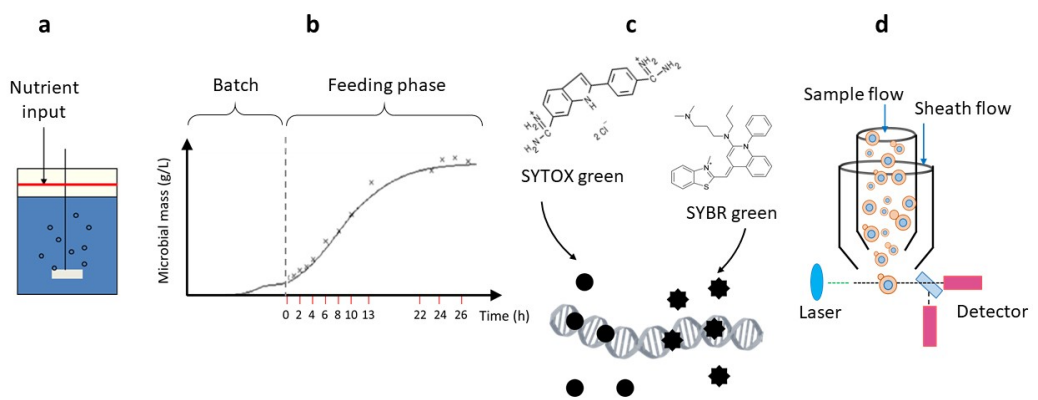

Fig 2. Overview of the experimental workflow. A fed-batch culture of Saccharomyces cerevisiae was performed in a stirred bioreactor (a) and sampled at different times during the cultivation starting from time 0 corresponding to a 15 $\mathrm{h}$ batch-cultivation (b). Fixed cells were stained (c) with either SYTOX Green or SYBR Green dyes for DNA detection. Finally, cells were analyzed by flow cytometer (d) as described in Materials and Methods.

https://doi.org/10.1371/journal.pone.0248382.g002

Cell samples were collected at different times during the cultivation run up to $26 \mathrm{~h}$ of the feeding phase (see also Fig 2a) to determine cell mass (optical density at $590 \mathrm{~nm}$ and dry weight determination) and perform FCM analysis.

In parallel to the fed-batch culture, a batch culture was set up with the same culture medium to collect yeast cells at 0.D.590 $=0,6$ (exponential cells) and after 7 days (starved cells), to be used as reference samples in FCM analysis.

For FCM analysis, samples were centrifuged $(500 \mathrm{~g}, 5 \mathrm{~min}$ ) to pellet cells and discard the culture medium. Then, cells were re-suspended and fixed in $75 \%$ ethanol, added dropwise under continuous vortexing to avoid cell agglomeration.

Fixed cell were centrifuged, treated with $1 \mathrm{mg} \mathrm{ml}^{-1}$ DNase-free RNAse A (Sigma) and stained with SYTOX Green $\left(1 \mu \mathrm{M}\right.$, Invitrogen ${ }^{\mathrm{m}}, \lambda$ ex $\left.504 \mathrm{~nm} / \lambda \mathrm{em} 523 \mathrm{~nm}\right)$ or SYBR Green $\left(1 \mu \mathrm{M}\right.$, Invitrogen ${ }^{\mathrm{nw}}, \lambda$ ex $\left.497 \mathrm{~nm} / \lambda \mathrm{em} 518 \mathrm{~nm}\right)$. Cells were acquired by Gallios Flow cytometer, equipped with 3 lasers ( $405 \mathrm{~nm}, 488 \mathrm{~nm}, 633 \mathrm{~nm}$, Beckman Coulter, Milan, Italy) and data were analysed with Kaluza Analysis Software v. 2.1 (Beckman Coulter).

\section{Results}

\section{Identification of cell cycle stages in a fed-batch culture of S. cerevisiae}

The fed-batch culture, which allowed yeast population to increase up to a maximal value of biomass, was sampled at different times of the feeding phase (from 0 to $26 \mathrm{~h}$ ). From each sample, cells were isolated and stained either with SYBR or SYTOX Green dyes in order to assess the dynamic changes of DNA content during S. cerevisiae cell cycle (Fig 2) which together with the evaluation of cell size allowed the identification of the different cell cycle phases.

In parallel, both stains were used to identify cell cycle profiles of exponential and starved yeast cells. In particular, the exponential cells, collected from a $15 \mathrm{~h}$ batch culture, was regarded as reference sample (Fig 3). Here, the distribution of cell sizes (forward scatter, FSC-A) and the content of cellular DNA (green fluorescence, FL1-A) individually plotted $v s$ cell count or combined in dot plots (FSC-A vs FL1-A) are reported for exponential (Fig 3a) and starved cells (Fig 3b), respectively.

For all the analysed stages, the percentage of cells in each cell cycle stage was similar for both dyes. The graphical results of SYBR Green and SYTOX Green staining for exponential cells were comparable: both dyes allowed a clear and precise definition of the cell cycle phases (G1, S, M and G2/M), as evidenced by the dot plots of FSC-A vs FL1-A and the histograms of 


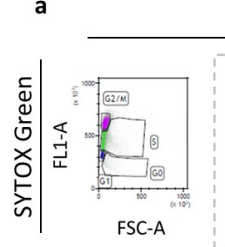

Exponential

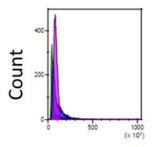

FSC-A
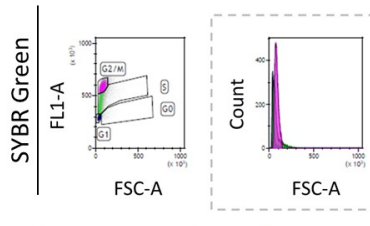

FSC-A

$\bullet \mathrm{G} 0 \bullet \mathrm{G} 1 \bullet \mathrm{S} \bullet \mathrm{G} 2 / \mathrm{M}$

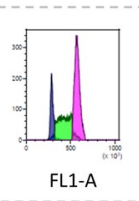

b

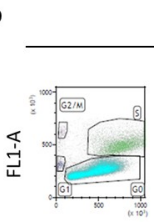

Starved
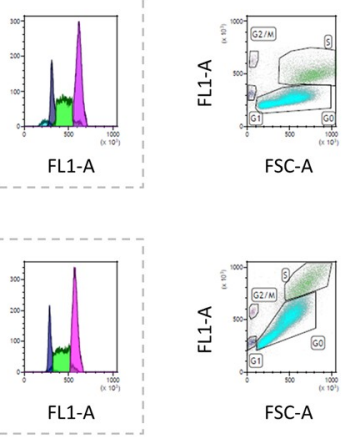
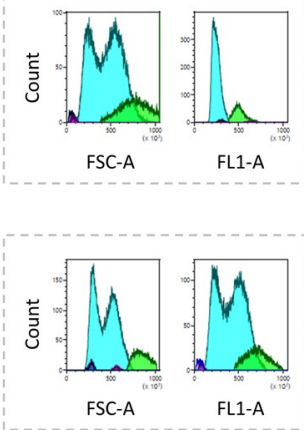

Fig 3. Flow cytometric analysis of S. cerevisiae cells from a batch culture, during exponential (a) and final starvation (b) phases, stained with SYTOX Green and SYBR Green dyes. Dashed rectangles group the monodimensional analysis of forward scatter signal (FSC-A) and green fluorescence (FL1-A), representing cell size and DNA content per cell, respectively, vs cell count. In the dot plots on the right of each panel, G0, G1, S, and G2/M cell cycle stages are identified according to both FSC-A and FL1-A.

https://doi.org/10.1371/journal.pone.0248382.g003

FSC-A and FL1-A signals. The DNA content distribution of exponential cells will be used as reference for subsequent analyses.

Conversely, in the case of starved cells (Fig 3b) a more complex situation was evident. Indeed, considering the cell size (FSC-A), the staining with both SYBR Green and SYTOX Green highlighted a substantial increase and a less homogeneous distribution in both $\mathrm{S}$ and G0 phases. In detail, as clearly shown in the relative histograms, the FSC-A of S phase identified one population with a wider distribution of cell sizes, whereas the FSC-A of G0 phase identified two different populations with two single peaked values. Interestingly, while the cell cycle profile of samples stained with SYTOX Green was consistent with the expected distribution of DNA content, the FL1-A signal was affected by the size distribution (FCS-A signal) in samples stained with SYBR Green (Fig 3b, FL1-A histograms).

From Fig 3, it is clear that an easier and more accurate analysis of the yeast cell cycle comes from the simultaneous evaluation of DNA content and cell size (significant variable during the yeast growth). Consequently, to analyse the progression of the cell cycle over time, the monodimensional analysis (histogram) cannot be used alone. The bi-dimensional analysis represented by dot plots (FL1-A vs FSC-A), by considering also cell dimension, becomes fundamental for a clearer and more accurate interpretation of the results, thus avoiding the noninformative artefacts of mono-dimensional analysis (especially after staining with SYBR Green).

We then analysed the cell cycle phases of cells collected during the fed-batch run, represented by a yeast population grown under a continuous but progressively decreasing supply of nutrients. In Fig 4, the analysis of some representative cell samples collected at different times $(0,6,12,22,26 \mathrm{~h})$ during the feeding phase is shown, to make a comparison of the SYBR Green and SYTOX Green outputs. Moreover, in Fig 4 FL1-A histograms are shown in parallel to dot plots in order to confirm that the bi-dimensional analysis gives rise to an easier identification of cell cycle phases. Interestingly, the distribution of cell size in $\mathrm{S}$ phase gradually widens from time 0 of the feeding run, corresponding to a batch culture of a $15 \mathrm{~h}$ (see Material and Methods), up to $26 \mathrm{~h}$, and probably was fated to widen even more reaching the distribution observed in the reference starved culture (Fig $3 \mathrm{~b}$ ). Of note, the presence of two different 


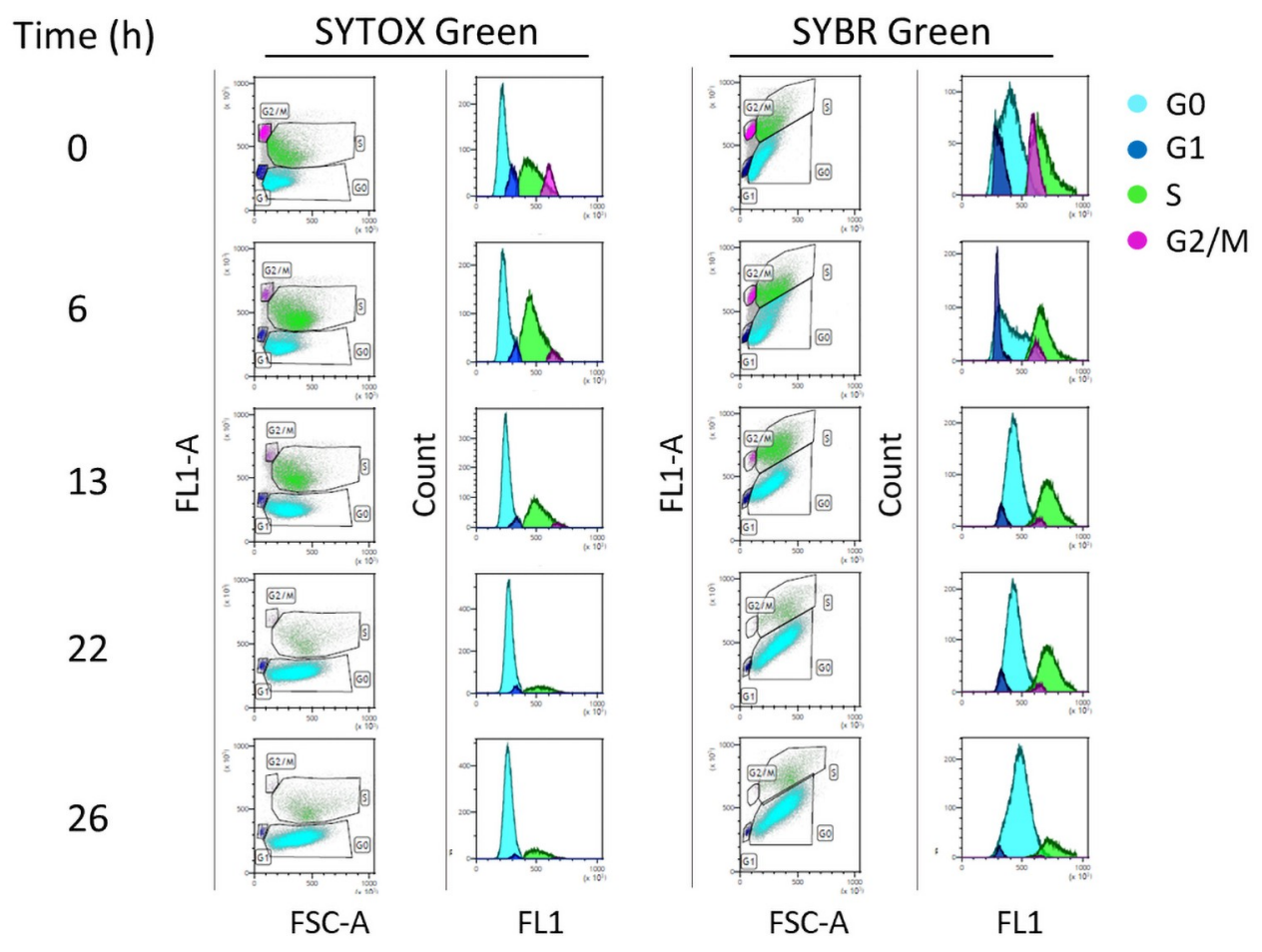

Fig 4. Analysis of S. cerevisiae cell cycle during the feeding phase of the cultivation by either SYTOX Green or SYBR Green staining. The figure shows both bi-dimensional (dot plots, FL1-A vs FSC-A) and mono-dimensional analysis (histograms of FL1-A).

https://doi.org/10.1371/journal.pone.0248382.g004

populations in the $\mathrm{G} 0$ phase is not observed in the $0-26 \mathrm{~h}$ interval, probably indicating a phenomenon occurring in a more advanced culture or in starved conditions.

The green fluorescence intensity is directly proportional to the amount of DNA present in each cell, and we used the green fluorescence intensity of the exponential phase as a reference value. Considering the fluorescent signal (FL1-A on the y axis of the dot plot), in Fig $3 \mathrm{~b}$ and in Fig 4, SYTOX Green and SYBR Green showed a different behaviour. Indeed, if we consider the characteristics of DNA content during the entire cell cycle (e.g. G2 cells have twice as much nuclear DNA as G1 cells) [25], the fluorescent signals of cells stained with SYTOX Green were more in line with those expected. Differently, when stained with SYBR Green, the fluorescence signal showed an apparent correlation with the cell size particularly in G0 and S phase where the fluorescence intensity becomes higher as the cell size increases (Figs $3 \mathrm{~b}$ and 4).

In Fig 5 the percentage of cells in each phase of the cell cycle during the feeding phase, detected using SYTOX Green, is reported showing the overall trend over the run.

Of note, the population of cells in $\mathrm{G} 0$ increases with the proceeding of the feeding run while that in $\mathrm{S}$ phase showed an opposite trend, particularly evident from $10 \mathrm{~h}$ after the beginning of the run. Moreover, in the last point of the feeding run $(26 \mathrm{~h})$ the percentage of cells in each cell cycle phase was comparable to that of the starved phase. In detail, by comparing the values of the $26 \mathrm{~h}$ feeding run and those of the starved reference sample (\% GO $=82,28 \pm 3,7 v s 81,88$ $\pm 2,94 ; \% \mathrm{G} 1=3,20 \pm 0,77$ and $2,43 \pm 2,05, \% \mathrm{~S}=13,61 \pm 2,45$ and $15,19 \pm 4,85 ; \% \mathrm{G} 2 / \mathrm{M}=0,91$ $\pm 0,51$ and $0,50 \pm 0,14$ ), it is evident that the percentage of cells in each phase of the yeast 


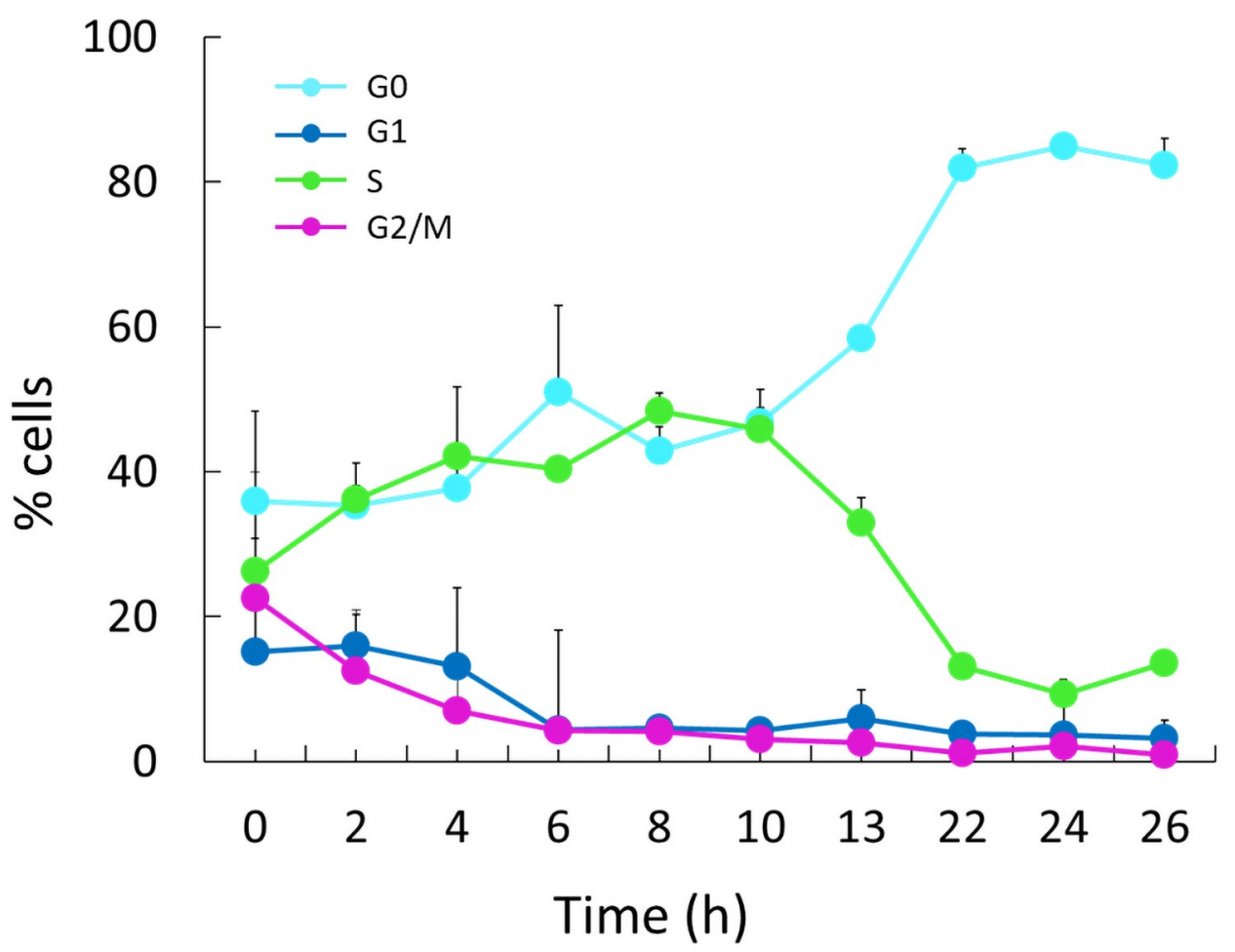

Fig 5. Distribution of cells in different cycle stages during the feeding phase of a S. cerevisiae cultivation. Only positive standard deviations are reported in the graph.

https://doi.org/10.1371/journal.pone.0248382.g005

population cultured in fed-batch approached a starvation condition, in concomitance with the progressive reduction of the nutrient feeding rate along the run.

\section{Discussion}

The yeast Saccharomyces cerevisiae is a reference model for biological systems widely used in many industrial applications $[1,2]$. The CEN.PK 2-1C strain used in the study can be considered as a reference strain. Indeed, it belongs to the CEN.PK family of isogenic laboratory strains with all possible combinations of the auxotrophic markers ura3, his3, leu2, and trp1. The CEN.PK strain family was constructed with the express aim of meeting the requirements of physiologists, geneticists, and engineers [33]. These strains display good performance in standard transformation tests and cultivation under well-defined conditions, so they are commonly used in studies related to cell growth rates and product formation, such as heterologous protein production.

In the context of industrial processes, where a critical point is the real-time monitoring of the bioprocess, FCM has been applied to control the microbial performance in bioreactors $[18,34]$.

Recently, FCM has been used as a sensitive and reliable tool for the real-time monitoring of the relative proportion of cells for each cell cycle stage in different times of an S. cerevisiae batch culture [32]. Since this study recommended SYTOX and SYBR Green as most suitable DNA-binding dyes [32], we used both and the cell size parameter to determine the different phases of the cell cycle of a S. cerevisiae population growing in a fed-batch bioreactor and compared results to define the best method of analysis. 
The bi-dimensional analysis represented by dot plots of FSC-A and FL1-A (cell size and green fluorescence, respectively) and also suggested by Zhang et al. [35] allows the rapid evaluation of two parameters the changing of which characterizes the cell cycle of budding yeast and avoids the confusing artefacts of the mono-dimensional analysis.

Our results highlighted two main features. The first one is related to the fluorescent signal. Although SYTOX Green and SYBR Green outputs are comparable in the exponential phase (Fig 3a), the SYTOX Green performs better than SYBR Green. In fact, as shown in Figs 3b and 4, the SYTOX Green staining allows to clearly identify all phases of cell cycle in yeast starved culture as well as during the whole feeding run. SYTOX Green identifies better the differences in the DNA content between $S$ and G2/M phase, which are expected to be higher in G2/M phase [25].

Both the two dyes, SYTOX Green and SYBR Green, bind with high affinity the DNA $[36,37]$. The main difference is that SYBR green penetrates also fixed intact cells, while SYTOX Green easily penetrates cells with compromised membranes [38-40]. This is not a problem since cell membranes are permeabilized by the fixative process in our experiments. Further, the staining with SYBR Green has been found to be more affected than SYTOX Green by nonspecific binding of the dye to sediments and debris [41-43], so the increased fluorescent signal that we found after staining yeast cells with SYBR green can be explained by a specific interaction of the dye with residual particles present in the samples. Moreover, it is known that SYBR green binds both nuclear and mitochondrial DNA [44] and it could be also possible that it binds even preferentially to mitochondrial DNA [45]. Nevertheless, further analysis is required to completely clarify the different affinity for mitochondrial and nuclear DNA of the two dyes.

The second feature is related to the cell size, and it is common to both stains: the less homogeneous distribution of cell size in S and G0 phase (Figs $3 \mathrm{~b}$ and 4). This can be related to the gradual increase of cellular asynchrony [46-48]. Considering the fraction represented by G0 cells, the heterogeneous size is expected according to previous findings identifying in stationary cultures sub-populations characterized by different morphologic and physiological properties, i.e smaller and larger cells [49-52].

Regarding the $S$ phase, since during that phase most of cell growth occurs in the bud [53], we can assume that the different cellular size detected in $\mathrm{S}$ phase depends on the different sizes of emerging buds.

Interestingly, if we consider the dimension of cells in the G1 phases as a standard for a cell after cytokinesis, from our results, we can assume that in the $S$ phase two phenomena coexist (Figs $3 \mathrm{~b}$ and 4). Firstly, an overall increase in cell dimension that could be dependent from a weaker control of cellular size and secondly, the growth of bud cells can be not accompanied by a proper cellular division, as previously observed [46]. Consequently, even if ready to divide, the mother and the daughter remain physically bound and the FCM device fails to consider them as two single and separate events.

Of note, it has been demonstrated that yeast cells can enter in G0 from each cell cycle phase [54]. Hence, the fact that the distribution of dimensions in G0 phase shows a profile similar to that of cells in $S$ phase could be an evidence that the major proportion of cells in our culture entering $\mathrm{G} 0$ derives from $S$ phase.

This phenomenon could probably explain the presence of two different G0 populations in the starved culture. Cells smaller in size are failing to re-enter the cell cycle while those bigger in size can represent the population of cells which exit cell cycle during the $\mathrm{S}$ phase. Finally, from $10 \mathrm{~h}$ after the beginning of the feeding phase, for each sampled time, the increment of G0 fraction and the reduction of $S$ fraction are quantitatively comparable (Fig 5). This reinforces the hypothesis that most of the cells in G0 phase derive from S phase. 


\section{Conclusions}

In this study, the cell cycle along the time course of a S. cerevisiae fed-batch culture has been evaluated on the basis of cell size and DNA content variation by using the two recommended dyes SYBR Green and SYTOX Green. Despite the comparable outputs in batch exponential phase of growth, SYTOX Green staining performed better than SYBR Green in the identification of all cell cycle phases of a starved culture, as well as during the whole feeding phase of a S. cerevisiae fed-batch culture. Despite the difficulties in fully standardizing the analytical methods to obtain comparable results, the bi-dimensional representation has proven to be effective for characterizing the cell cycle of budding yeast grown in a fed-batch bioreactor and thus inferring on its physiological status. This could pave the way for the development of a suitable strategy of analysis in the perspective of a real-time monitoring of a yeast fed-batch bioprocess applicable with minimal effort to industrial processes.

\section{Author Contributions}

Conceptualization: Elisabetta de Alteriis.

Data curation: Emanuela Palomba.

Formal analysis: Valentina Tirelli, Massimo Sanchez.

Investigation: Elisabetta de Alteriis, Carmine Landi.

Methodology: Emanuela Palomba, Valentina Tirelli, Palma Parascandola, Massimo Sanchez.

Project administration: Massimo Sanchez.

Supervision: Stefano Mazzoleni, Massimo Sanchez.

Writing - original draft: Emanuela Palomba, Valentina Tirelli.

Writing - review \& editing: Emanuela Palomba, Valentina Tirelli, Elisabetta de Alteriis, Palma Parascandola, Carmine Landi, Stefano Mazzoleni, Massimo Sanchez.

\section{References}

1. Parapouli M, Vasileiadis A, Afendra A-S, Hatziloukas E. Saccharomyces cerevisiae and its industrial applications. AIMS Microbiol. 2020; 6(1):1-31. https://doi.org/10.3934/microbiol.2020001 PMID: 32226912

2. Nandy SK, Srivastava RK. A review on sustainable yeast biotechnological processes and applications. Microbiol Res [Internet]. 2018; 207:83-90. Available from: http://www.sciencedirect.com/science/ article/pii/S0944501317308674. https://doi.org/10.1016/j.micres.2017.11.013 PMID: 29458873

3. Tsao GT. Principles of microbe and cell cultivation, S. John Pirt, Halsted Press, Division of John Wiley and Sons, New York, 274 pages, \$34.00. AIChE J [Internet]. 1976; 22(3):621. Available from: https:// aiche.onlinelibrary. wiley.com/doi/abs/10.1002/aic.690220342.

4. Mattanovich D, Branduardi P, Dato L, Gasser B, Sauer M, Porro D. Recombinant protein production in yeasts. Methods Mol Biol. 2012; 824:329-58. https://doi.org/10.1007/978-1-61779-433-9_17 PMID: 22160907

5. Riesenberg D, Guthke R. High-cell-density cultivation of microorganisms. Appl Microbiol Biotechnol [Internet]. 1999; 51(4):422-30. Available from: https://doi.org/10.1007/s002530051412. PMID: 10341426

6. Reed G, Nagodawithana TW. Baker's yeast production. In: Yeast technology. Springer; 1991. p. 261314.

7. Mazzoleni S, Landi C, Cartenì F, de Alteriis E, Giannino F, Paciello L, et al. A novel process-based model of microbial growth: self-inhibition in Saccharomyces cerevisiae aerobic fed-batch cultures. Microb Cell Fact. 2015 Jul; 14:109. https://doi.org/10.1186/s12934-015-0295-4 PMID: 26223307 
8. Barford JP, Hall RJ. A mathematical model for the aerobic growth of Saccharomyces cerevisiae with a saturated respiratory capacity. Biotechnol Bioeng [Internet]. 1981; 23(8):1735-62. Available from: https://onlinelibrary.wiley.com/doi/abs/10.1002/bit.260230806.

9. Lei F, Rotbøll M, Jørgensen SB. A biochemically structured model for Saccharomyces cerevisiae. J Biotechnol [Internet]. 2001; 88(3):205-21. Available from: http://www.sciencedirect.com/science/article/pii/ S0168165601002693. https://doi.org/10.1016/s0168-1656(01)00269-3 PMID: 11434967

10. Jones KD, Kompala DS. Cybernetic model of the growth dynamics of Saccharomyces cerevisiae in batch and continuous cultures. J Biotechnol. 1999; 71(1-3):105-31. https://doi.org/10.1016/s01681656(99)00017-6 PMID: 10483102

11. Vembadi A, Menachery A, Qasaimeh MA. Cell Cytometry: Review and Perspective on Biotechnological Advances. Front Bioeng Biotechnol [Internet]. 2019; 7:147. Available from: https://www.frontiersin.org/ article/10.3389/fbioe.2019.00147. https://doi.org/10.3389/fbioe.2019.00147 PMID: 31275933

12. Paiva B, Gutiérrez NC, Rosiñol L, Vídriales M-B, Montalbán M-Á, Martínez-López J, et al. High-risk cytogenetics and persistent minimal residual disease by multiparameter flow cytometry predict unsustained complete response after autologous stem cell transplantation in multiple myeloma. Blood. 2012 Jan; 119(3):687-91. https://doi.org/10.1182/blood-2011-07-370460 PMID: 22128143

13. Gauthier DJ, Sobota JA, Ferraro F, Mains RE, Lazure C. Flow cytometry-assisted purification and proteomic analysis of the corticotropes dense-core secretory granules. Proteomics [Internet]. 2008; 8 (18):3848-61. Available from: https://onlinelibrary.wiley.com/doi/abs/10.1002/pmic.200700969. https:// doi.org/10.1002/pmic.200700969 PMID: 18704904

14. Phinney DA, Cucci TL. Flow cytometry and phytoplankton. Cytometry. 1989 Sep; 10(5):511-21. https:// doi.org/10.1002/cyto.990100506 PMID: 2776567

15. Marie D, Simon N, Guillou L, Partensky F, Vaulot D. Flow Cytometry Analysis of Marine Picoplankton. In 2000. p. 421-54.

16. Brehm-Stecher BF. Flow Cytometry. In: Batt CA, Tortorello M Lou, editors. Encyclopedia of Food Microbiology (Second Edition) [Internet]. Second Edi. Oxford: Academic Press; 2014. p. 943-53. Available from: http://www.sciencedirect.com/science/article/pii/B9780123847300001270.

17. Vees CA, Veiter L, Sax F, Herwig C, Pflügl S. A robust flow cytometry-based biomass monitoring tool enables rapid at-line characterization of $\mathrm{S}$. cerevisiae physiology during continuous bioprocessing of spent sulfite liquor. Anal Bioanal Chem. 2020 Apr; 412(9):2137-49. https://doi.org/10.1007/s00216020-02423-z PMID: 32034454

18. Díaz M, Herrero M, García LA, Quirós C. Application of flow cytometry to industrial microbial bioprocesses. Biochem Eng J [Internet]. 2010; 48(3):385-407. Available from: http://www.sciencedirect.com/ science/article/pii/S1369703X09002563.

19. Lú Chau T, Guillán $A$, Roca E, Núñez MJ, Lema JM. Population dynamics of a continuous fermentation of recombinant Saccharomyces cerevisiae using flow cytometry. Biotechnol Prog. 2001; 17(5):951-7. https://doi.org/10.1021/bp010090r PMID: 11587589

20. Bridier A, Hammes F, Canette A, Bouchez T, Briandet R. Fluorescence-based tools for single-cell approaches in food microbiology. Int J Food Microbiol. 2015 Nov; 213:2-16. https://doi.org/10.1016/j. ijfoodmicro.2015.07.003 PMID: 26163933

21. Longin C, Petitgonnet C, Guilloux-Benatier M, Rousseaux S, Alexandre H. Application of flow cytometry to wine microorganisms. Food Microbiol. 2017 Apr; 62:221-31. https://doi.org/10.1016/j.fm.2016.10. 023 PMID: 27889152

22. Sommer S. Monitoring the Functionality and Stress Response of Yeast Cells Using Flow Cytometry. Microorganisms. 2020 Apr; 8(4). https://doi.org/10.3390/microorganisms8040619 PMID: 32344655

23. Alberghina L, Ranzi BM, Porro D, Martegani E. Flow cytometry and cell cycle kinetics in continuous and fed-batch fermentations of budding yeast. Biotechnol Prog [Internet]. 1991; 7(4):299-304. Available from: https://doi.org/10.1021/bp00010a002. PMID: 1367344

24. Alberghina L, Porro D. Quantitative flow cytometry: analysis of protein distributions in budding yeast. A mini-review. Yeast. 1993 Aug; 9(8):815-23. https://doi.org/10.1002/yea.320090802 PMID: 8212889

25. Rosebrock AP. Analysis of the Budding Yeast Cell Cycle by Flow Cytometry. Cold Spring Harb Protoc. 2017 Jan; 2017(1). https://doi.org/10.1101/pdb.prot088740 PMID: 28049776

26. Nicoletti I, Migliorati G, Pagliacci MC, Grignani F, Riccardi C. A rapid and simple method for measuring thymocyte apoptosis by propidium iodide staining and flow cytometry. J Immunol Methods. 1991 Jun; 139(2):271-9. https://doi.org/10.1016/0022-1759(91)90198-o PMID: 1710634

27. Mendes-Ferreira A, Sampaio-Marques B, Barbosa C, Rodrigues F, Costa V, Mendes-Faia A, et al. Accumulation of non-superoxide anion reactive oxygen species mediates nitrogen-limited alcoholic fermentation by Saccharomyces cerevisiae. Appl Environ Microbiol. 2010 Dec; 76(24):7918-24. https:// doi.org/10.1128/AEM.01535-10 PMID: 20952643 
28. Jayakody LN, Kadowaki M, Tsuge K, Horie K, Suzuki A, Hayashi N, et al. SUMO expression shortens the lag phase of Saccharomyces cerevisiae yeast growth caused by complex interactive effects of major mixed fermentation inhibitors found in hot-compressed water-treated lignocellulosic hydrolysate. Appl Microbiol Biotechnol. 2015 Jan; 99(1):501-15. https://doi.org/10.1007/s00253-014-6174-9 PMID: 25359478

29. Salma M, Rousseaux S, Sequeira-Le Grand A, Divol B, Alexandre H. Characterization of the Viable but Nonculturable (VBNC) State in Saccharomyces cerevisiae. PLoS One. 2013; 8(10):e77600. https://doi. org/10.1371/journal.pone.0077600 PMID: 24204887

30. Cui J. Visualization of the Budding Yeast Cell Cycle. In 2017.

31. Ferrezuelo F, Colomina N, Palmisano A, Garí E, Gallego C, Csikász-Nagy A, et al. The critical size is set at a single-cell level by growth rate to attain homeostasis and adaptation. Nat Commun. 2012; 3:1012. https://doi.org/10.1038/ncomms2015 PMID: 22910358

32. Delobel $P$, Tesnière C. A Simple FCM Method to Avoid Misinterpretation in Saccharomyces cerevisiae Cell Cycle Assessment between G0 and Sub-G1. PLoS One [Internet]. 2014; 9(1):1-8. Available from: https://doi.org/10.1371/journal.pone.0084645. PMID: 24392149

33. van D JP, Bauer J, Brambilla L, Duboc P, Francois JM, Gancedo C, et al. An interlaboratory comparison of physiological and genetic properties of four Saccharomyces cerevisiae strains. Enzyme Microb Technol. 2000 Jun; 26(9-10):706-14. https://doi.org/10.1016/s0141-0229(00)00162-9 PMID: 10862876

34. Schuler M. Real-time monitoring and control of the specific growth rate in yeast fed-batch cultures based on Process Analytical Technology monitoring tools such as biocalorimetry and spectroscopy. In 2012.

35. Zhang H, Siede W. Analysis of the budding yeast Saccharomyces cerevisiae cell cycle by morphological criteria and flow cytometry. Methods Mol Biol. 2004; 241:77-91. https://doi.org/10.1385/1-59259646-0:77 PMID: 14970647

36. Thakur S, Cattoni DI, Nöllmann M. The fluorescence properties and binding mechanism of SYTOX green, a bright, low photo-damage DNA intercalating agent. Eur Biophys J. 2015 Jul; 44(5):337-48. https://doi.org/10.1007/s00249-015-1027-8 PMID: 26024786

37. Dragan Al, Pavlovic R, McGivney JB, Casas-Finet JR, Bishop ES, Strouse RJ, et al. SYBR Green I: fluorescence properties and interaction with DNA. J Fluoresc. 2012 Jul; 22(4):1189-99. https://doi.org/ 10.1007/s10895-012-1059-8 PMID: 22534954

38. Lebaron $P$, Catala $P$, Parthuisot $N$. Effectiveness of SYTOX Green stain for bacterial viability assessment. Appl Environ Microbiol. 1998 Jul; 64(7):2697-700. https://doi.org/10.1128/AEM.64.7.2697-2700. 1998 PMID: 9647851

39. Roth BL, Poot M, Yue ST, Millard PJ. Bacterial viability and antibiotic susceptibility testing with SYTOX green nucleic acid stain. Appl Environ Microbiol. 1997 Jun; 63(6):2421-31. https://doi.org/10.1128/ aem.63.6.2421-2431.1997 PMID: 9172364

40. Jones LJ, Singer VL. Fluorescence microplate-based assay for tumor necrosis factor activity using SYTOX Green stain. Anal Biochem. 2001 Jun; 293(1):8-15. https://doi.org/10.1006/abio.2001.5116 PMID: 11373072

41. Wobus A, Bleul C, Maassen S, Scheerer C, Schuppler M, Jacobs E, et al. Microbial diversity and functional characterization of sediments from reservoirs of different trophic state. FEMS Microbiol Ecol. 2003 Dec; 46(3):331-47. https://doi.org/10.1016/S0168-6496(03)00249-6 PMID: 19719563

42. Morono $\mathrm{Y}$, Terada $\mathrm{T}$, Kallmeyer J, Inagaki F. An improved cell separation technique for marine subsurface sediments: applications for high-throughput analysis using flow cytometry and cell sorting. Environ Microbiol. 2013 Oct; 15(10):2841-9. https://doi.org/10.1111/1462-2920.12153 PMID: 23731283

43. SANTIBÁÑEZ PA, McCONNELL JR, PRISCU JC. A flow cytometric method to measure prokaryotic records in ice cores: an example from the West Antarctic Ice Sheet Divide drilling site. J Glaciol [Internet]. 2016/05/02. 2016; 62(234):655-73. Available from: https://www.cambridge.org/core/article/flowcytometric-method-to-measure-prokaryotic-records-in-ice-cores-an-example-from-the-west-antarcticice-sheet-divide-drilling-site/5D6EA2194D34D57E05AB3C4C70187CFB.

44. Briggs $C$, Jones M. SYBR Green I-induced fluorescence in cultured immune cells: a comparison with Acridine Orange. Acta Histochem. 2005; 107(4):301-12. https://doi.org/10.1016/j.acthis.2005.06.010 PMID: 16139877

45. Jevtic V, Kindle P, Avilov S V. SYBR Gold dye enables preferential labelling of mitochondrial nucleoids and their time-lapse imaging by structured illumination microscopy. PLoS One. 2018; 13(9):e0203956. https://doi.org/10.1371/journal.pone.0203956 PMID: 30226899

46. Johnston GC, Pringle JR, Hartwell LH. Coordination of growth with cell division in the yeast Saccharomyces cerevisiae. Exp Cell Res. 1977 Mar; 105(1):79-98. https://doi.org/10.1016/0014-4827(77) 90154-9 PMID: 320023 
47. Johnston GC, Ehrhardt CW, Lorincz A, Carter BL. Regulation of cell size in the yeast Saccharomyces cerevisiae. J Bacteriol. 1979 Jan; 137(1):1-5. https://doi.org/10.1128/jb.137.1.1-5.1979 PMID: 368010

48. Müller $\mathrm{S}$, Harms $\mathrm{H}$, Bley $\mathrm{T}$. Origin and analysis of microbial population heterogeneity in bioprocesses. Curr Opin Biotechnol. 2010 Feb; 21(1):100-13. https://doi.org/10.1016/j.copbio.2010.01.002 PMID: 20138500

49. Allen C, Büttner S, Aragon AD, Thomas JA, Meirelles O, Jaetao JE, et al. Isolation of quiescent and nonquiescent cells from yeast stationary-phase cultures. J Cell Biol. $2006 \mathrm{Jul} ; 174(1): 89-100$. https:// doi.org/10.1083/jcb.200604072 PMID: 16818721

50. Aragon AD, Rodriguez AL, Meirelles O, Roy S, Davidson GS, Tapia PH, et al. Characterization of differentiated quiescent and nonquiescent cells in yeast stationary-phase cultures. Mol Biol Cell. $2008 \mathrm{Mar}$; 19(3):1271-80. https://doi.org/10.1091/mbc.e07-07-0666 PMID: 18199684

51. Davidson GS, Joe RM, Roy S, Meirelles O, Allen CP, Wilson MR, et al. The proteomics of quiescent and nonquiescent cell differentiation in yeast stationary-phase cultures. Mol Biol Cell. $2011 \mathrm{Apr} ; 22$ (7):988-98. https://doi.org/10.1091/mbc.E10-06-0499 PMID: 21289090

52. Svenkrtova A, Belicova L, Volejnikova A, Sigler K, Jazwinski SM, Pichova A. Stratification of yeast cells during chronological aging by size points to the role of trehalose in cell vitality. Biogerontology. 2016 Apr; 17(2):395-408. https://doi.org/10.1007/s10522-015-9625-5 PMID: 26614086

53. Soifer I, Robert L, Amir A. Single-Cell Analysis of Growth in Budding Yeast and Bacteria Reveals a Common Size Regulation Strategy. Curr Biol. 2016 Feb; 26(3):356-61. https://doi.org/10.1016/j.cub. 2015.11.067 PMID: 26776734

54. Wei $W$, Nurse $P$, Broek $D$. Yeast cells can enter a quiescent state through $G 1, S$, G2, or $M$ phase of the cell cycle. Cancer Res. 1993 Apr; 53(8):1867-70. PMID: 8467507 